\title{
Failure Analysis Leads Teens into Materials Science
}

$\mathrm{W}$

hen the members of the ASM International Foundation wanted a program to motivate high school students to consider a career in materials science, they decided to create an intensive, hands-on, experiential, and fun Materials Camp. The first camp, held for 30 students last August at the ASM Materials Engineering Institute, Materials Park, Ohio, had as its central focus a set of real-life failure analysis projects.

In fact, of all the activities in which the students participated, the failure investigations were rated the most valuable in the formal post-program evaluations. The second most valuable activity was the block of lectures from failure analysis experts Dr. Robert Pond, Jr.; Dr. Macintyre Louthan, Jr.; and Frauke Hogue.

Pond, president, $M$. Structures, Inc., and lecturer, Johns Hopkins University and Loyola College, presented an "Introduction to Metallurgy" and "Fun in Metals," a well-known presentation developed by his father. Louthan, senior advisory engineer, Savannah River Laboratory of Westinghouse Savannah River Company, delivered his famous "Why Stuff Falls Apart-The Process of Failure Analysis." Hogue, an independent metallography consultant, provided an introduction to "Microstructure Interpretation."

Outside of these formal lectures, instruction was either individual or hands-on. To learn how to do some of the basic activities and how to use the lab equipment, Jes Stautzenberger, assistant director, Materials Engineering

Institute, explained that the students "made a metallurgical comparison of wrought iron nails from the late 1850s, steel nails from the 1960s, and new steel nails. The students conducted mechanical tests, metallographic examinations, and action. Students had access to all the equipment in the multi-million dollar laboratories as well as an extensive technical reference library.

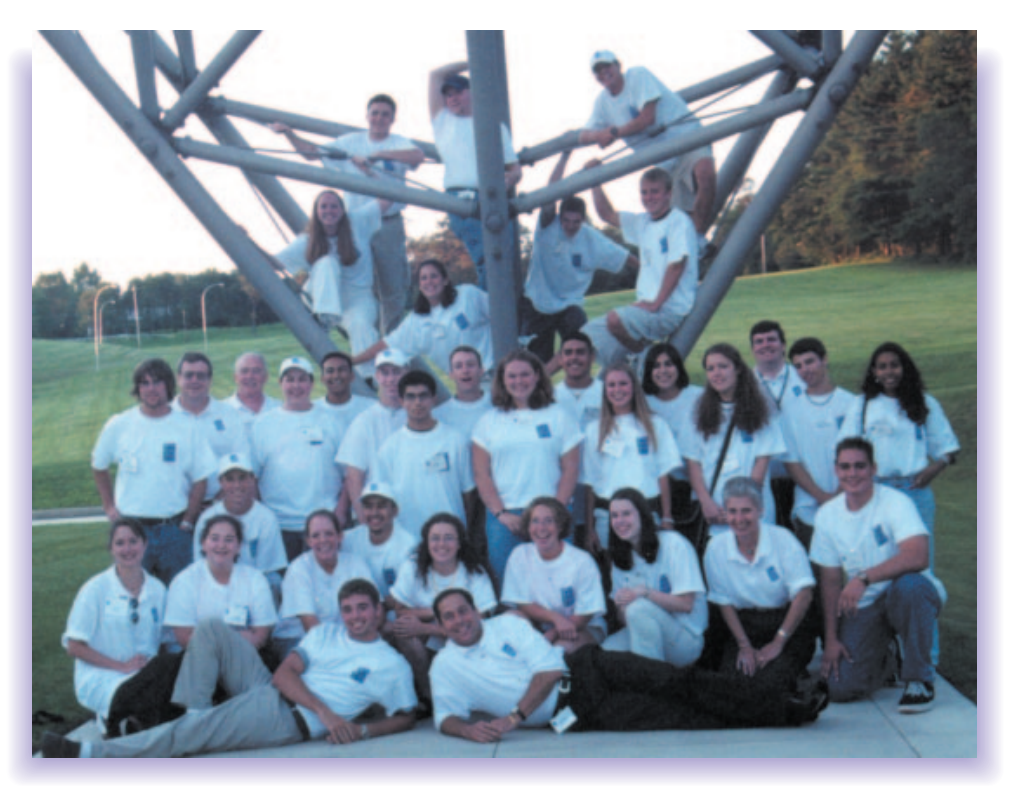

The Materials Camp faculty, students, and organizers celebrate the end of a stimulating educational experience.

SEM/EDX examinations to compare how the nails were processed, and to determine the cleanliness of the materials, the microstructures, and the mechanical properties.”

The group of campers was divided into six self-named teams, each with its own volunteer faculty member. The teams each had different real-life failures to analyze, and they were charged with both identifying the root cause and recommending corrective
The catch was that they only had two and a half days to complete their analysis. But this group of dynamic young people, with guidance from their fearless instructors, accomplished the task and managed to have a good time doing it. "I learned a great deal about teamwork," said camper Arben Billusha, “... materials science can be a lot of fun after all!"

Faculty member, Dr. Daniel Dennies, senior principal engineer/scientist, Boeing Company, said, "The challenge for the instructors was ... how much to guide the team and how much to let the team run its course. I tried to make it as real life as possible, and it does not get any more real than performing a failure investigation with a set time of two and a half days. All decisions were made by the team, no matter how small or how significant."

Dennies' team, The Dome Monkeys, attempted to discover why the bolts in the lower section of ASM's $110 \mathrm{ft}$. tall geodesic dome were damaged. Their preliminary work included making a fault tree with a listing of possible failure sources in material, design, and assembly. They 
proceeded to review blueprints, inspect the dome, and interview pertinent personnel in order to understand the bolt usage, installation procedures, and historical problems. Visual and metallographic examination, in combination with SEM analysis, revealed the damage in the bolt thread was caused by an impact loading from the radial direction that matched the area of bolt thread to clevis pin alignment.

They concluded that the Alcoa 245T4 aluminum material used to make the bolts was too soft to resist deformation from the mating clevis pin during dome movement. Dome movement is a normal occurrence caused by a number of sources including thermal expansion, lightning strikes, earthquakes, and structural failures in other areas of the dome. The group recommended using stainless steel bolts with rolled threads, since they are stronger as well as corrosion resistant. Since the use of stainless steel bolts would create a potential galvanic corrosion problem with the aluminum structural components, the group also recommended using a sealing compound on the bolts during installation.

The Insane Metallurgist Posse, led by Hogue, was tasked with analyzing a cracked, corroded, broken piece of

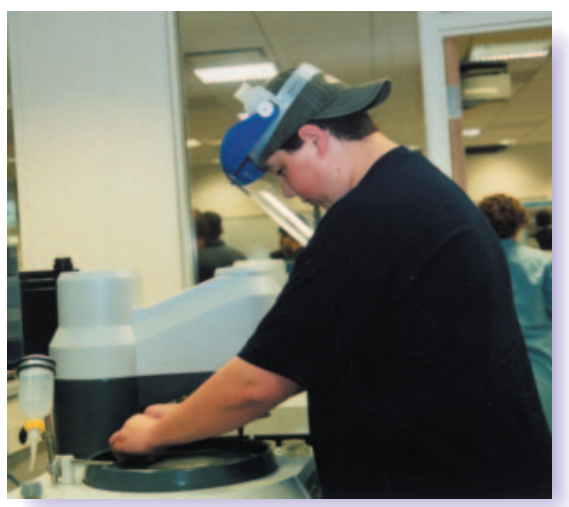

Brandon Ribic polishes a sample in the metallurgy lab.

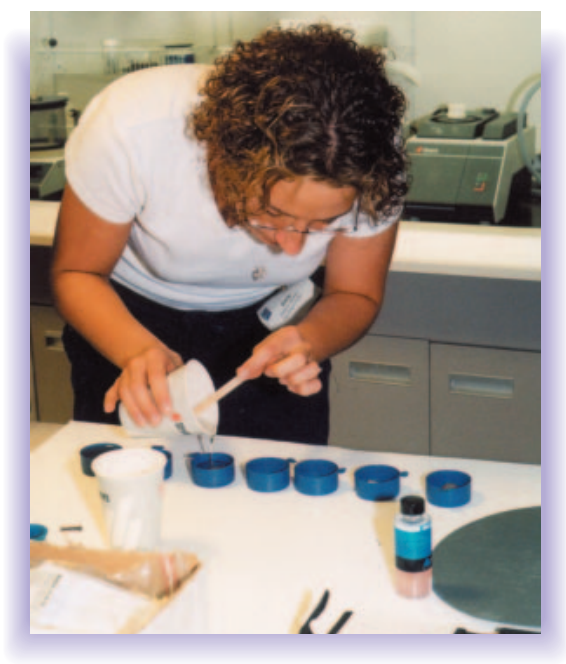

Emily Roettger pots samples so she can examine them under a microscope.

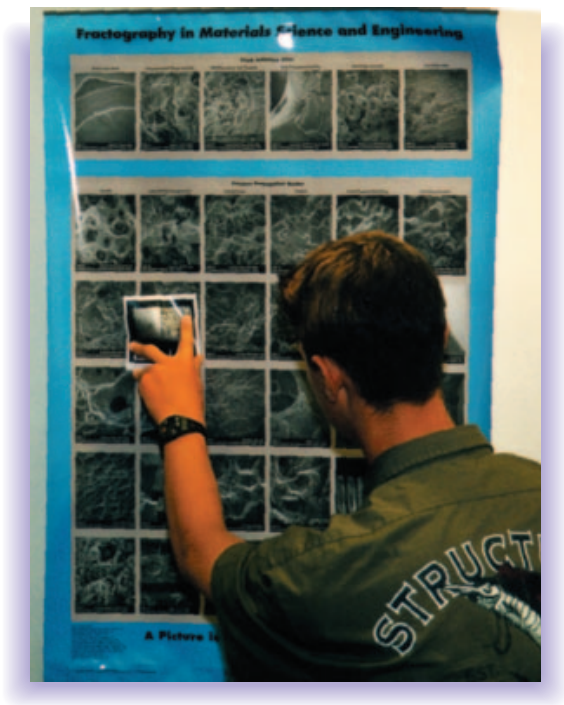

Paul Dailey attempts to match a photo taken with the scanning electron microscope to illustrations on the fractography chart.

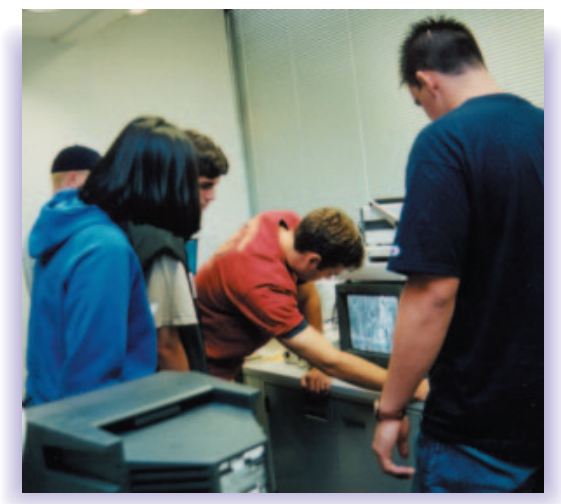

The L.L. Pac Ink. Group examines the fracture surface of their failure using a video microscope. brass tube plate from a heat exchanger. Their strategy included identifying the metal, creating a new fracture site for reference, finding out why the metal corroded, and researching possible solutions. They discovered that the metal was a cartridge brass (70\% copper and $30 \%$ zinc). Galvanic corrosion caused by aerated water had dissolved the brass, leached out the zinc, and redeposited the copper as a spongy mass-a process called dezincafication. Some possible solutions the team suggested were using red brass or brass with less zinc, adding tin or antimony, and deaerating the water.

Flex Industries Inc., led by Janice L. Klansky, manager, educational services, Buehler Ltd., performed a failure analysis on a U-bolt from a CAT tractor. The bolt had little resistance to pressure; one even cracked when it was being installed. The team learned that the bolt was processed using shearing, heat treatment, hardening and tempering, threading, cold form, cleaning, pickling, plating, baking, and coating. The group theorized that the failure was caused by the quenching, cold bending processes, or corrosion. They concluded that the bending caused tensile stress, the alkaline cleaning solution was possibly corrosive, and

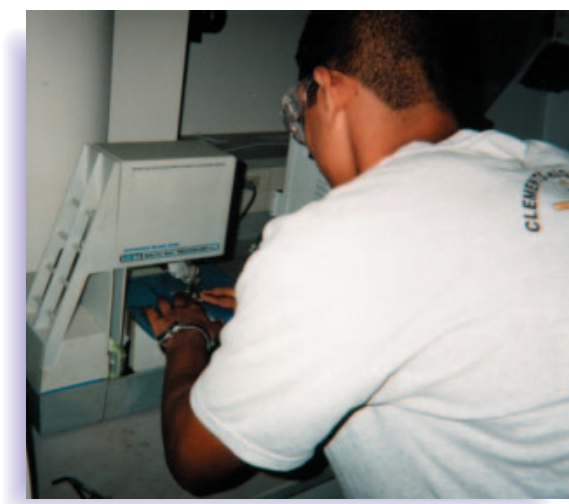

Peter Shab uses the diamond band saw to prepare a sample. 


\section{Failure Analysis Leads Teens into Materials Science}

that these forces led to stress corrosion cracking. The recommendations included: sandblasting to remove heat treat scales, limiting the sodium hydroxide bath to less than five minutes, keeping the pickle dip brief, and continuing to coat with zinc dichromate.

A failure of brass rivets was the problem posed to Frog Consultants, led by Michael B. Connelly, CQE, Casey Products. The team was "hired" by Casey Products, which purchases the brass rivets from Trojan and then distributes them to Caterpillar. Casey Products prefers Trojan's price and service, but Trojan's rivets were cracking when assembled to brake shoe linings. The failure investigation revealed that the hardness specification for the rivet doesn't allow enough ductility for it to pass a rollover test without cracking the rivet. Frog Consultants recommended a change in the hardness specification for the brass rivet and suggested using steel instead of brass.

Four Girls, a Guy, and a HUGE Failure, Inc., led by Stephen Glancy,

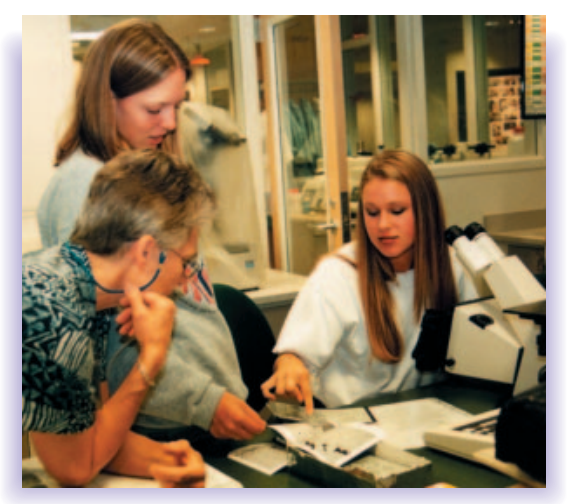

Frauke Hogue (left) helps Becca Hammon and Rebecca Douglas (right) analyze their micrographs and examine a sample under the microscope. director of technical services, Struers Inc., attempted to discover why a steam pipe burst. They theorized that the pipe had been exposed to higher than recommended operating temperatures. They performed SEM analysis including EDS, hardness testing, and metallographic examination. Their recommendation was that all pipes within the same proximity be examined for effects of overheating and be replaced if necessary.

LL Pac Ink., along with Pond, investigated a galvanized fire protection pipe that had failed after short service. The thin wall pipe had split nine inches along a weld seam, and the piping system had suffered 14 pinhole leaks at weld fusion lines prior to the burst. The team considered several causal factors for the failure: too much water pressure in the pipe; aggressive fluid and corrosion in the pipe; and a lack of fusion welding flaw.

Stereo-optic microscopy and SEM observation showed no corrosion on the separation surface at the burst; however, there was light corrosion pitting on the inside surface of the pipe. EDS analysis indicated no zinc coating on the inside of the pipe, although a white zinc oxide powder was present. Differential interference contrast was used on metallographic samples and showed no zinc coating on the inside of the pipe. There was proper zinc coating on the outside of the pipe. The strip was hot dip galvanized prior to forming into a pipe, so that zinc was present at one time inside the pipe.

Calculations demonstrated that the pipe section was adequate to contain the fire protection water pressure and that a major loss of wall thickness was required to allow the burst. Corrosion was not evident along the weld line and the internal corrosion was too sporadic and light to explain the necessary loss of wall thickness. The team concluded that the burst was caused by an incomplete weld in the pipe. The burst only occurred after subsequent loss of ligaments from internal corrosion at the welding flaw. Additionally, the team found that the zinc protection in the pipe had failed and that the system would eventually leak. They recommended a conversion from the fire protection piping to a conventional, thick-walled, steel piping system.

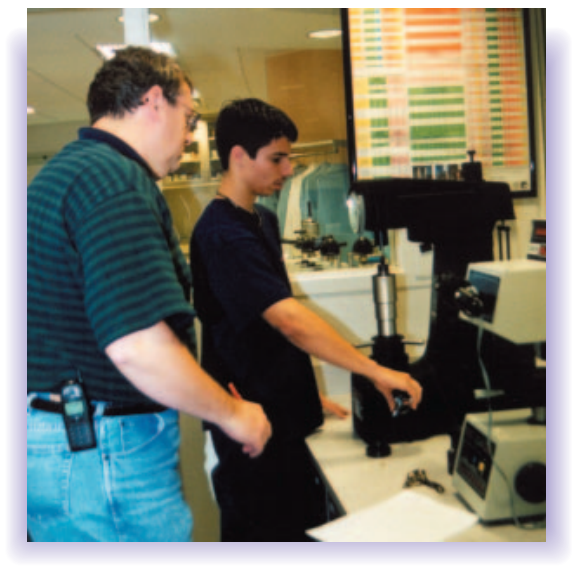

Michael B. Connelly shows Mitch Kadel how to do a hardness test. 
Comments about this first Materials Camp from the participants, faculty, and organizers were very positive. Dennies noted that the camp "was a great venue in which to introduce our profession to some very gifted young people. The last evening of the camp, these young people were thanking the instructors, and all I wanted to do was to thank them."

The ASM International Foundation Board plans to have another camp next year and eventually add a second camp on the West Coast and a third camp in Europe.

Carla Sly, ASM International, 9639 Kinsman Road, Materials Park, $\mathrm{OH}$ 44073; e-mail: csly@asminternational. org.

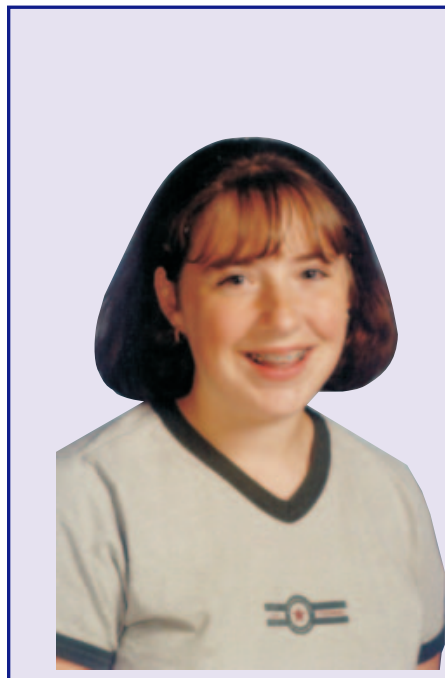

\section{What Materials Camp Meant To Me}

by Emily Roettger, Wartburg Central High School, Wartburg, Tenn.

$\Lambda$ SM's Materials Camp was a great experience. The learning experiences I had while there are priceless. Upon arrival, we were treated as guests of honor. The first day at the headquarters, we got to hear two great presentations. After the talks, we discussed our group projects that we would have for the next week. They were all failures in real life

"...knowing that I was talking to world-renowned metallurgists was incredibly thrilling." situations.

The one that my group received to analyze was the "U-Bolt". My group leader, Janice Klansky, from Buehler Ltd., released bits of information to us at different times throughout the week. We studied quenching, fatigue, stress cracks, and corrosion. We used machinery that was out of this world, such as SEMs. The goal was for us to be exposed to as much as we could in the materials science field in a week. We worked on the "U-Bolt" for about three days. Right before our deadline, we found the real cause of the cracking (after a long, drawn-out process!). We gave a presentation to the ASM Foundation Board and told about our experience.

For me, Materials Camp was a wonderful experience. I met many great people. All the camp instructors were absolutely great, and knowing that I was talking to world-renowned metallurgists was incredibly thrilling. Upon returning home, I did a presentation for the ASM Oak Ridge Chapter, which had sponsored me. It was Foundation Members night, so it was really crowded. Everyone was really welcoming, and after the presentation I was complimented many, many times. In addition, the head of the materials science department at UTK (University of Tennessee, Knoxville) was recruiting me, and I was asked to be a student member of the Oak Ridge Chapter. All in all, Materials Camp was one of the best experiences I have had. I hope that other students will be able to have the same experiences.

\section{Wartburg Central High School}

Emily's high school is one of the few in the United States that offers exposure to materials science. At Wartburg Central High School, Dan Shoemaker teaches a one-credit science elective that explores the material properties of polymers, metals, ceramics, glass, and composites. The hands-on lab course places an emphasis on manufacturing, material testing, and material processing. The model for the course was developed at Richland High School, which is just outside the Pacific Northwest Lab, Richland, Wash. 